\title{
Bryophyte cover estimation in a boreal black spruce forest using airborne lidar and multispectral sensors
}

\author{
Scott D. Peckham*, Douglas E. Ahl, Stith T. Gower \\ Department of Forest and Wildlife Ecology, University of Wisconsin, 1630 Linden Drive, Madison, WI 53706, USA
}

\section{A R T I C L E I N F O}

\section{Article history:}

Received 20 May 2008

Received in revised form 20 January 2009

Accepted 7 February 2009

Available online xxxx

\section{Keywords:}

Bryophyte cover

SLICER

CASI

Boreal forest

Carbon cycling

Sphagnum

Moss

\begin{abstract}
A B S T R A C T
Bryophytes are the dominant ground cover vegetation layer in many boreal forests and in some of these forests the net primary production of bryophytes exceeds the overstory. Therefore it is necessary to quantify their spatial coverage and species composition in boreal forests to improve boreal forest carbon budget estimates. We present results from a small exploratory test using airborne lidar and multispectral remote sensing data to estimate the percentage of ground cover for mosses in a boreal black spruce forest in Manitoba, Canada. Multiple linear regression was used to fit models that combined spectral reflectance data from CASI and indices computed from the SLICER canopy height profile. Three models explained 63-79\% of the measured variation of feathermoss cover while three models explained 69-92\% of the measured variation of sphagnum cover. Root mean square errors ranged from 3-15\% when predicting feathermoss, sphagnum, and total moss ground cover. The results from this case study warrant further testing for a wider range of boreal forest types and geographic regions.
\end{abstract}

(C) 2009 Elsevier Inc. All rights reserved.

\section{Introduction}

Bryophytes are an important ground cover vegetation layer of most boreal forests. Bryophytes consist of several major functional groups such as feathermosses (Pleurozium schreberi and Hylocomium splendens), Sphagnum, and lichens (Cladonia) and inhabit a wide range of environmental conditions. Feathermosses occur in the more closedcanopy, well-drained black spruce (Picea mariana) forests and Sphagnum mosses occur in the more open-canopy, poorly-drained black spruce forests and peatlands (Bisbee et al., 2001). Lichens often occur in excessively drained open-canopy boreal conifer forests. Bryophyte net primary production (NPP) comprises a significant fraction of the total NPP in boreal black spruce forests (Bisbee et al., 2001; Gower et al., 1997). Bryophytes are important in both the hydrologic and carbon cycles of boreal ecosystems at large spatial scales (Bond-Lamberty et al., 2007, in press).

Our understanding of the important role of bryophytes to the boreal forest carbon and water cycles has rapidly increased in the last several decades (Skre and Oechel, 1981; Turetsky, 2003) and emphasizes the need to include their contribution to the boreal forest biome budget. To do this however, an approach to estimate the species composition and spatial coverage of bryophytes is required. Rapalee et al. (2001) used landcover type associations derived from the

\footnotetext{
* Corresponding author. Tel.: +1 608265 5628; fax: +1 6082629922. E-mail address: sdpeckha@wisc.edu (S.D. Peckham).
}

Advanced Very High Resolution Radiometer (AVHRR) to produce a moss map for the BOREAS study region. However, the accuracy of the AVHRR landcover classification in poorly-drained areas (where bryophytes dominate) was low (Steyaert et al., 1997). AVHRR is a four- to six-band multispectral instrument with a spatial resolution of $1.1 \mathrm{~km}$ that has been carried by the NOAA series of satellites since 1979 .

The canopy structure of boreal forests presents both challenges and opportunities to using remote sensing to characterize bryophytes. The highly-clumped, open-canopy, and abundant understory and ground layers make accurately estimating properties such as leaf area index (LAI) from space-born sensors difficult (Serbin et al., 2009). On the other hand, the open canopy exposes the understory and bryophytes to incident solar radiation and hence, provides the possibility to use airborne and spaceborne sensors to quantify bryophyte species composition and leaf area. The ecophysiology and carbon budget are dramatically different between bryophytes and other sympatric vascular plants in both open- and closed-canopy black spruce ecosystems (O'Connell et al., 2003b; Whitehead \& Gower, 2001).

The airborne lidar instrument SLICER (Scanning Lidar Imager of Canopies by Echo Recovery) has been used to determine forest canopy profiles (Harding et al., 2001), estimate canopy structure parameters including leaf area index (Lefsky et al., 1999a; Ni-Meister et al., 2001), model gross primary production (Kotchenova et al., 2004), and predict above-ground biomass (Lefsky et al., 1999b, 2002). With a laser transmitter operating at $1064 \mathrm{~nm}$ (Harding et al., 2001), SLICER return waveforms provide a good estimate of the canopy height 
profile (CHP), and contain a signal returned from the interaction with the ground layer vegetation. The Compact Airborne Spectrographic Imager (CASI) has been used to map biophysical parameters of boreal forests (Chen et al., 1999). CASI measures the spectral radiance in the visible and near-infrared portions of the electromagnetic spectrum at a spatial resolution of less than $5 \mathrm{~m}$.

The objective of this study was to use field data collected during BigFoot (Campbell et al., 1999) in combination with SLICER and CASI acquired during the Boreal Ecosystem-Atmosphere experiment (BOREAS) (Sellers et al., 1995) to quantify the ground surface covered by bryophytes at the Northern Study Site-old black spruce (NOBS). We hypothesized that the ground portion of the SLICER return was correlated to bryophyte coverage in the boreal forest. Also, we hypothesized that a combination of multispectral and lidar would provide better estimates of bryophyte cover than a single sensor. This study is relevant as there has been little success in quantifying the coverage of bryophytes at large spatial scales and currently the contribution of bryophytes to the signal measured by satellite-born multispectral instruments and active radar instruments is largely unknown.

\section{Methods}

\subsection{Study area}

We used data covering the NOBS study site, a 160 year-old black spruce stand, approximately $50 \mathrm{~km}$ west of Thompson, Manitoba, Canada. Data were originally collected as part of the BOREAS and
BigFoot experiments during 1996 and 1999, respectively. The study area is centered on an eddy-covariance flux tower located at $55.88^{\circ} \mathrm{N}$, $98.48^{\circ} \mathrm{W}$. The terrain is gently rolling in the study area, but slight differences in elevation can result in significant vegetation changes. The BigFoot plots sampled for moss ground cover, the SLICER shot locations, and the overall location of the site are shown in Fig. 1. Annual temperature at the nearby Thompson airport averaged $-3.2{ }^{\circ} \mathrm{C}$ and precipitation averaged $517 \mathrm{~mm}$ per year from $1971-$ 2000 (Environment Canada, 2008). Black spruce is the dominant overstory tree species at NOBS, with some tamarack (Larix laricina) occurring in the poorly-drained areas (Gower et al., 1997). Ground cover is dominated by mosses, both sphagnum (Sphagnum spp) and feather (Pleurozium and Hylocomium), and reindeer lichens (Cladonia spp) are also present. Understory species include bog birch (Betula glandulosa), Labrador tea (Ledum groenlandicum), and willow (Salix spp.) in the poorly-drained areas.

\subsection{SLICER data processing}

SLICER data (Harding, 2000) was ordered through the ORNL DAAC (http://daac.ornl.gov/). The compact disc that contained the binary data included IDL (ITT, 2006) code to browse the data files. We used a modified version of 'convertd.pro' along with additional code developed by the Forest Ecosystem Ecology lab at the University of Wisconsin to extract SLICER shots based on their spatial location. Using the location of BigFoot field plots at NOBS, we determined which SLICER shots (the center point) were within $5 \mathrm{~m}$ of plot center. The SLICER data had about a $10 \mathrm{~m}$ footprint on the ground. The terrain

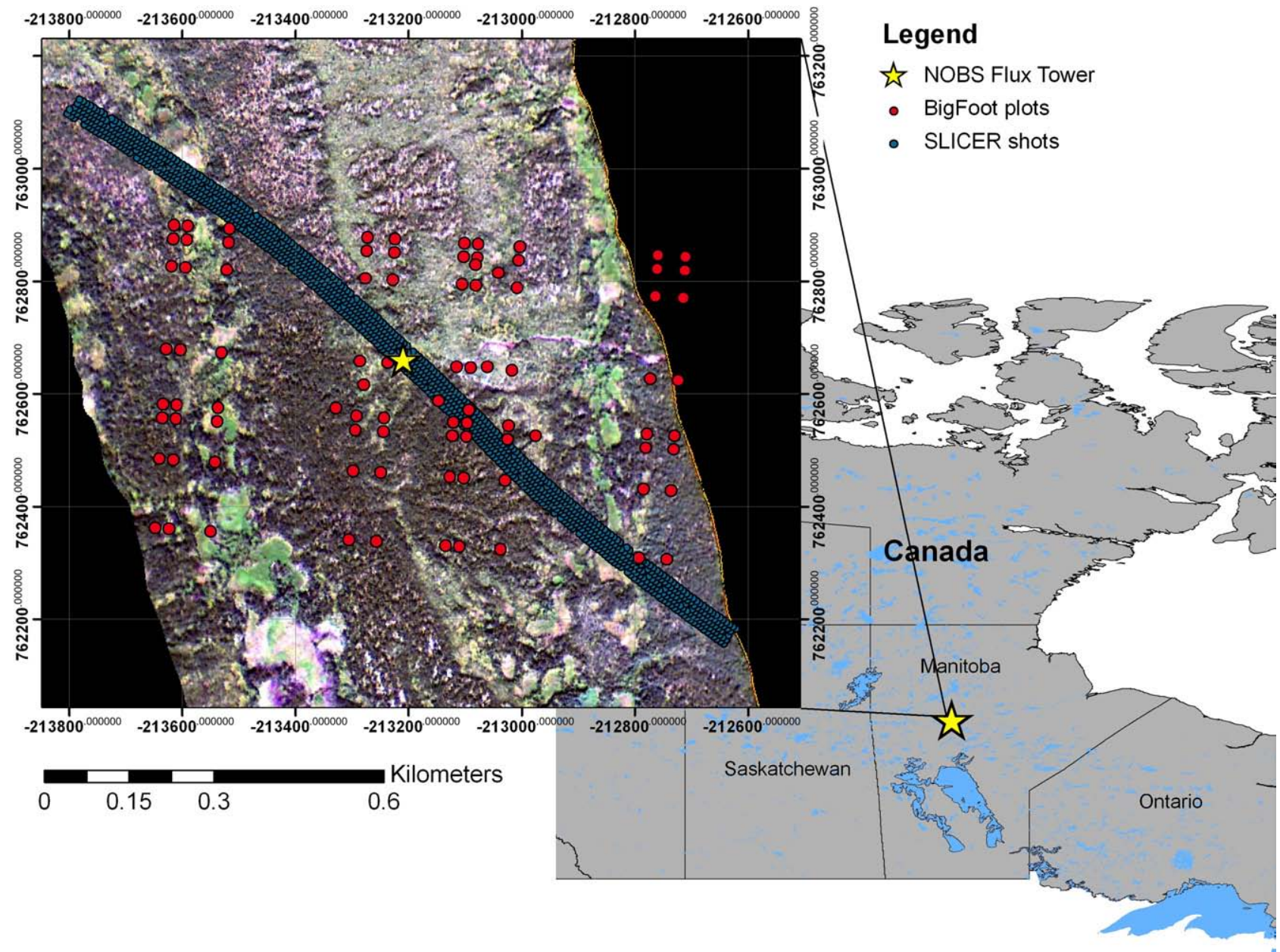

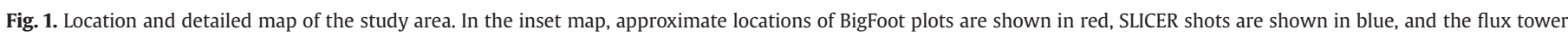
location is displayed with a yellow star in both the inset and the Canadian province map. The CASI imagery, a composite of bands 6 , 7, and 13 is displayed underneath. 
is gently rolling in the study area, with a slope between 0 and $4 \%$ (Bond-Lamberty, unpublished data). We acknowledge the potential effects of slope on the lower portion of the waveform (or the entire waveform), but we assume the effects of slope on the majority of SLICER returns at NOBS to be negligible. More importantly, we found no evidence in the literature that SLICER waveforms to response to forest biophysical properties or above-ground biomass was affected by slope (i.e. Lefsky et al., 1999b, 2002). We address the potential effects of micro topography in the discussion. The entire waveform, as well as the ground start, ground peak, ground end, and noise were extracted and written to a text file. Another important assumption we made was that the SLICER footprints fell on a representative area of the canopy. The footprint size of $10 \mathrm{~m}$ is significantly larger than the crown diameter of boreal black spruce and larger than the average gap size, which implies that each SLICER footprint should encompassed canopy and gap area. The forest canopy in the study area is fairly continuous, the transition between well- and poorly-drained forest types (uplands to muskegs) is gradual (Campbell et al., 1999). The only possible edge effects caused by misregistration of the SLICER data would be due to unforested areas such as fens or open water bodies. Upon inspection of the CASI imagery and associated SLICER footprints we saw no evidence of errors introduced by proximity to either of these unforested areas. We acknowledge possible errors arising from imperfect alignment between field plots and slicer shots as well as the difference between collection dates of the SLICER and BigFoot data, although it is unlikely that there were significant shifts in ground cover percentages or LAI at plots in NOBS between 1996 and 1999.

Following the methods in Lefsky et al. (1999a), we removed background noise and transformed the raw digitizer counts from SLICER to relative canopy height profiles (scaled to 1 ). Using the method presented by Kotchenova et al. (2004), we computed foliage height profiles (FHP) scaled to site LAI. The sum of FHP and the maximum values were extracted for statistical analysis. Fig. 2 shows FHP's for 3 selected plots with varying moss ground cover. We also identified several indices based on the raw SLICER waveform to correlate the return to the bryophyte ground cover. Fig. 3 shows a raw SLICER signal for a representative site at NOBS. For each return waveform, we denoted $\mathrm{CA}(\mathrm{i})$ as the relative canopy return at any distance (SLICER return increment of $0.11 \mathrm{~m}$ ) above the ground, Sum_CA as the sum of CA from the top to bottom of the canopy (from points A to B in Fig. 3), and Sum_Grnd as the sum of the return from the ground (points B to C, Fig. 3). We estimated the SLICER canopy

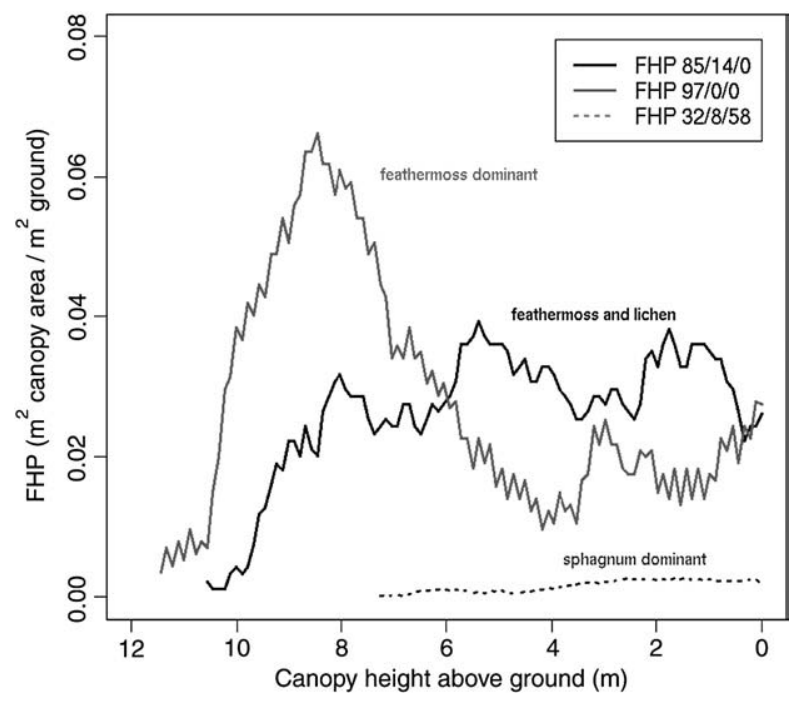

Fig. 2. Foliage height profiles for three plots at NOBS. The numbers associated with each plot in the figure legend refer to percent cover of feathermoss, lichen, and sphagnum, respectively.

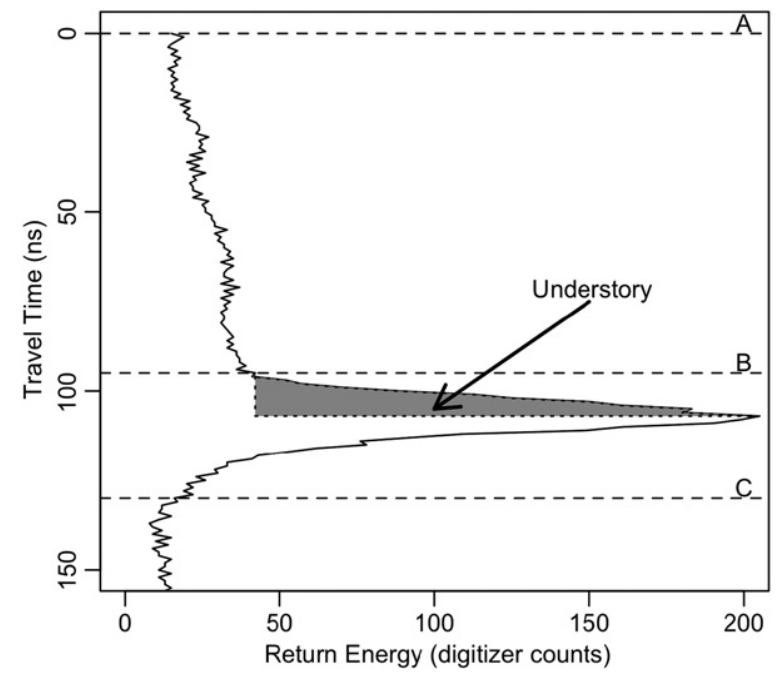

Fig. 3. Raw slicer waveform for a selected plot at NOBS. Important points in the waveform that were used in this study are marked by the dashed lines and associated capital letters. The top of canopy occurs at A. The beginning and end of the ground return are marked by B and $C$ respectively. Understory contribution was adapted from Lefsky et al. (1999a).

profile index (CHPI) that related the canopy portion of the SLICER return to the ground portion as follows in Eq. (1):

CHPI $=100 * \frac{\text { Sum_CA }- \text { Sum_Grnd }}{\text { Sum_CA }+ \text { Sum_Grnd }}$.

\subsection{CASI data processing}

CASI data (Miller, 2000) was obtained from the ORNL DAAC. The images were calibrated (Gray et al., 1997), atmospherically corrected using a variant of the 5 S radiation transfer code (O'Neill et al., 1997), and geocorrected using the flight GPS and altitude (Miller, 2000). These data were originally acquired on July 18, 1996 as a part of the BOREAS experiment. The CASI instrument was flown on the Chieftain Navajo aircraft and is capable of multiple view geometry, variable band configurations, and spatial resolution dependent on aircraft height. The imagery used in this study contained 14 spectral bands (Table 1) with pixel resolution of approximately $2 \mathrm{~m}$. The modeled reflectance data were extracted for pixels that occurred within the BigFoot plots.

We calculated several vegetation indices derived from CASI, including NDVI, enhanced vegetation index (EVI), and the ratio of

Table 1

CASI Configuration for the BOREAS study.

\begin{tabular}{lll}
\hline Channel & Center $(\mathrm{nm})$ & Bandwidth $(\mathrm{nm})$ \\
\hline 1 & 411.46 & 15.86 \\
2 & 442.2 & 10.38 \\
3 & 468.32 & 10.42 \\
4 & 487.01 & 10.44 \\
5 & 530.07 & 10.48 \\
6 & 554.47 & 10.5 \\
7 & 644.92 & 10.58 \\
8 & 665.73 & 10.6 \\
9 & 677.1 & 10.6 \\
10 & 704.61 & 12.52 \\
11 & 747.43 & 10.64 \\
12 & 774.14 & 10.64 \\
13 & 858.51 & 10.66 \\
14 & 869.11 & 12.58 \\
\hline
\end{tabular}

Shown are the spectral bands, center wavelength, and bandwidth in nanometers (adapted from description at http://daac.ornl.gov /boreas/RSS/r19cas96/comp/ RSS19_CASI_IMG_1996.txt). 
green to red bands. These indices were chosen based on their use in vegetation monitoring on other remote sensing platforms (MODIS, AVHRR, Landsat). Of these indices, the CASI normalized difference vegetation index (NDVI) (Eq. (2)) helped explain the observed variation in moss ground cover.

$\mathrm{NDVI}=\frac{b 13-b 8}{b 13+b 8}$

We applied a low-pass filter to the individual band reflectance data (i.e. B2low, B9low) to extract the background of the plot and remove the high frequency elements, which were likely sunlit tree crowns.

\subsection{Field data collection}

Field data from the BigFoot site centered on the NOBS flux tower were utilized in this study, the same tower used in the BOREAS experiment. The locations of the plots relative to the SLICER shots are shown in Fig. 1. Percent bryophyte cover data were collected as part of the above-ground net primary production data for BigFoot (Campbell et al., 1999; Gower and Kirschbaum, 2008). Each $10 \times 10 \mathrm{~m}$ plot (Fig. 1) contained ten $0.5 \mathrm{~m} \times 0.5 \mathrm{~m}$ subplots where percent bryophyte cover by major functional group (i.e. feathermoss, sphagnum, and lichen) was estimated visually (Bisbee et al., 2001; Campbell et al., 1999). Percent bryophyte cover was computed as the average value of the subplots. A total of 16 BigFoot plots coincided with SLICER shots.

\subsection{Regression modeling}

Percent feathermoss, sphagnum, and total bryophyte coverage were modeled using multiple linear regressions. Independent variables included those calculated from the SLICER and CASI data and their interactions. Model fit was assessed by Akaike's information criterion (AIC) and by examining the magnitude of the root mean square error and $p$-values for model coefficients. Models with low AIC, RMSE, and associated $p$-values were selected and presented here. In this paper, we presented the three best models each for feathermoss and sphagnum.

\section{Results}

\subsection{Feathermoss}

Feathermoss coverage ranged from 53 to 99, reindeer lichen from 0 to 28 , and sphagnum from 0 to $26 \%$. The three best models were fairly

Table 2

Statistics for the various model fits for feathermoss (FM), sphagnum (SP), and total (TOTAL) moss cover $(N=16)$.

\begin{tabular}{lllllll}
\hline Moss & MODEL & \multicolumn{1}{l}{ R } & $P$ & $R^{2}$ & RMSE & AIC \\
\hline FM & B2low & 37.92 & $<.0001$ & 0.73 & 8.18 & 115.6 \\
& CHPI B2low CHPI*B2low & 14.95 & 0.0002 & 0.79 & 7.82 & 129.6 \\
& Intercept & & 0.0013 & & & \\
& CHPI & 1.7 & 0.2167 & & & \\
& B2low & 11.84 & 0.0049 & & & \\
& CHPI*B2low & 1.79 & 0.2058 & & & \\
& CHPI NDVI & 11.29 & 0.0014 & 0.63 & 9.89 & 116.5 \\
& CHPI & 10.05 & 0.0074 & & & \\
& NDVI & 5.86 & 0.0308 & & & \\
SP & 33.63 & $<.0001$ & 0.69 & 5.12 & 106.8 \\
& CHPI & 75.57 & $<.0001$ & 0.92 & 2.78 & 103.3 \\
& CHPI CHPI*B2low & 34.37 & $<.0001$ & & & \\
& CHPI & 36.93 & $<.0001$ & & & \\
& CHPI*B2low & 26.24 & $<.0001$ & 0.86 & 3.73 & 121.3 \\
& CHPI B9low CHPI*B9low & 11.23 & 0.0052 & & & \\
& CHPI & 0.47 & 0.5073 & & & \\
TOTAL & B9low & 12.99 & 0.0026 & 0.46 & 12.28 & 135 \\
& B2low & 5.31 & 0.04 & 0.26 & 14.41 & 137.8 \\
\hline & CHPI & & & &
\end{tabular}

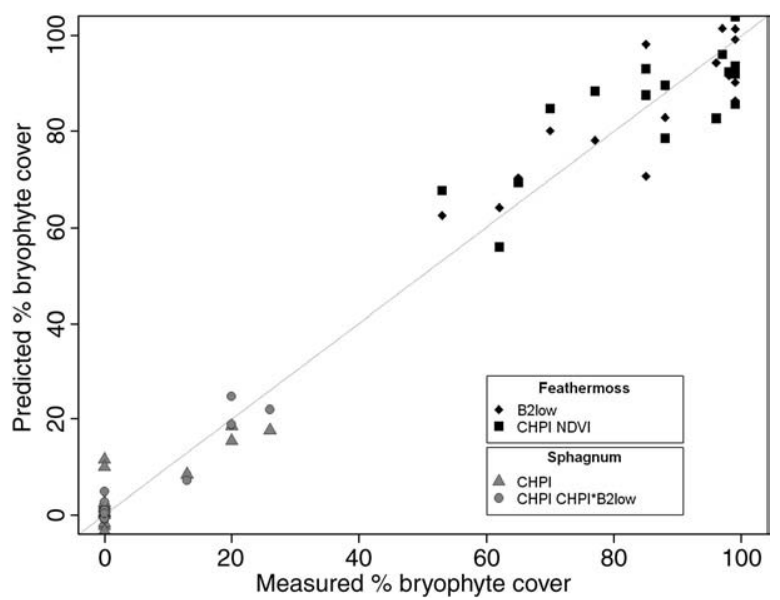

Fig. 4. Predicted vs. measured percentage moss ground cover. Two models are shown for both feathermoss (diamond and square) and sphagnum (triangle and circle). The diagonal line represents 1:1. Statistics for each model are provided in Table 2.

simple, with 1-3 independent variables each (Table 2). The best model for predicting feathermoss cover was the low-pass filtered band 2 of CASI (B2low) which had the lowest AIC, the second lowest RMSE $(8.18 \%)$, and explained $73 \%$ of the measured variation in feathermoss cover (Fig. 4). The model that included CHPI, B2low, and CHPI*B2low interaction had the lowest RMSE (7.82) but had the highest AIC (129.6). The model that combined the SLICER-derived CHPI and CASI NDVI had the largest RMSE (9.89) and explained the lowest amount of the measured variation in feathermoss percent cover (Table 2).

\subsection{Sphagnum}

Several sphagnum models were identified despite fewer observations of sphagnum than feathermoss cover. The SLICER-derived CHPI model had the largest RMSE (5.12) and lowest adjusted coefficient of variation (Table 2, Fig. 4). The model for predicting sphagnum cover included CHPI and CHPI*B2low as independent variables and had the smallest RMSE (2.78) and AIC (103.3), and the largest adjusted $R^{2}$ (0.92). The third model for predicting sphagnum included CHPI, B9low, and CHPI*B9low as independent variables (Table 2). This model had an RSME of 3.73 and accounted for $86 \%$ of the variance. It had the highest AIC of the sphagnum models (121.3), perhaps indicating the model was overfitted.

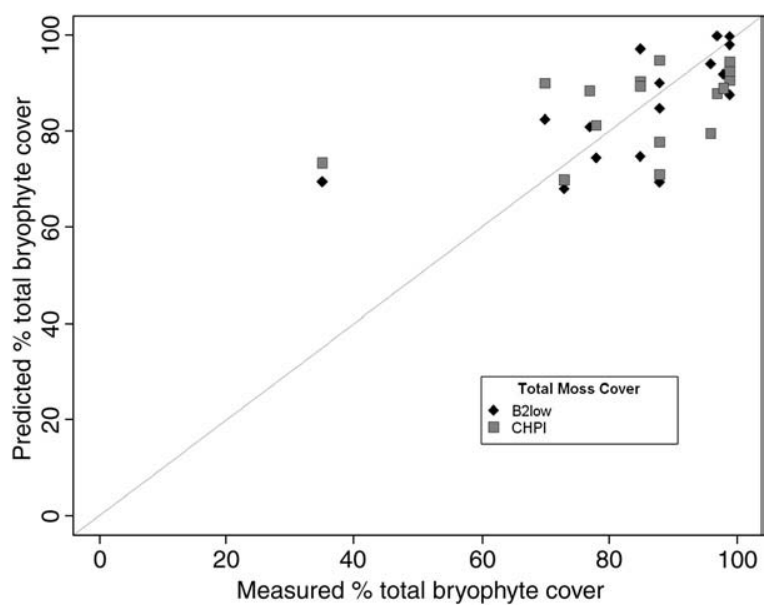

Fig. 5. Predicted vs. measured percentage total moss ground cover. Two models are shown, B2low (diamond) and CHPI (square). The diagonal line represents 1:1. 


\subsection{Total moss cover}

The combined model that included feathermoss and sphagnum was not as robust as specific models for each bryophyte type (Table 2). The two best models for predicting total moss cover (Fig. 5) were simple. The B2low model had the lowest RMSE and largest adjusted $R^{2}$ (0.46) while the CHPI model had the largest RMSE of all models (14.41) and the lowest adjusted $R^{2}(0.26)$.

\section{Discussion}

We observed a strong positive empirical relationship between measured percent ground cover of bryophytes and indices derived from SLICER and CASI data. While field data encompassed the complete range of total moss cover $(0-100 \%)$, sphagnum cover was lower (0-28\%) than feathermoss (56-99\%). We recognize that NOBS may not be indicative of all sites inhabited by bryophytes, and further research is warranted. However, the species composition of boreal forests is much simpler than temperate or tropical forests (Gower et al., 2001) and dominated by the same genera throughout. In general, the same indices (CHPI, B2low and their interaction) worked well for both sphagnum and feathermoss. Both CASI band 2 (442 nm) and the relative index of canopy signal to ground signal in SLICER produced model RMSEs of less than $10 \%$ when predicting feathermoss or sphagnum separately. More common vegetation indices used to characterize canopy greenness (simple ratio, NDVI, etc.) did not work particularly well for characterizing bryophyte cover in this study.

Few studies have measured spectral properties of boreal bryophytes. Bubier et al. (1997) reported that the reflectance in the near infra-red (NIR) spectra differed between sphagnum and feathermoss and may be indicative of cellular structure. They also noted that the narrow NIR peak $(0.85 \mu \mathrm{m})$ and red absorption of sphagnum greatly reduced the usefulness of traditional vegetation indices (NDVI, simple ratio), as corroborated by results from this study. The biophysical basis behind the success of using CASI band 2 and the ratio of ground to canopy return from SLICER to model moss cover is not clear. It is plausible that the low-pass filtered CASI band 2 is a surrogate for moss cover in NOBS plots relative to reflected signal from the canopy. Data from BondLamberty and Gower (2007) suggest that in well-drained black spruce stands, total bryophyte coverage decreased with increasing basal area once the stand reached maturity. This higher basal area leaves less ground surface area available for moss growth. Though the spectra of black spruce and the moss species differ most in the NIR and SWIR, our results suggest the subtle differences between the canopy and understory reflectance in band 2 across the plot is correlated to the percentage of the ground occupied by the bryophyte layer.

The ratio of ground return to canopy return (CHPI) was also a useful indicator of area occupied by bryophytes at NOBS, perhaps due to the NIR wavelength of the laser transmitter. Another possible explanation for the success observed here are the effects of the micro topography on the SLICER return. It is interesting to note that using CHPI in the model worked well for both feathermoss and sphagnum, the micro topography in the study region is dependent on the drainage type. The well-drained sites dominated by feathermoss exhibit very little variation in elevation. Of 144 points sampled on four, $6 \times 6 \mathrm{~m}$ plots, $95 \%$ of points fell within $10 \mathrm{~cm}$ of the plot mean (BondLamberty, unpublished data). In most cases (97\%), the micro topography in the well-drained stands is less than the vertical resolution of the SLICER data, and hence should have little effect on the lower portion of the waveform. In contrast, poorly-drained sites (slope $=0$ ) at NOBS, the sampled points varied by up to $0.3 \mathrm{~m}$ from the plot mean (Bond-Lamberty, unpublished data), which exceeds the vertical resolution of SLICER by almost 3 times. Thus, in sphagnum- dominated sites, the micro topography likely influences the lower portion of the SLICER waveform. Different plant communities inhabit the high and low elevations at these sites, and sphagnum coverage is highly correlated to the SLICER return in this case. It is this difference that perhaps explains our success at using the CHPI to model sphagnum cover. Using the CHPI to model feathermoss required the addition of the multispectral data to produce acceptable models. In this study, the model for estimating feathermoss which had the lowest RMSE and highest coefficient of variation utilized both CASI band 2 and CHPI.

The best models for total moss cover utilized only one sensor. This was surprising since RMSE values were quite low for both feathermoss and sphagnum when modeled separately. When total moss coverage was modeled, the combination of the best metrics for modeling feathermoss and sphagnum individually did not produce better results than using CHPI or B2low alone. Plots used in this study had high total moss coverage, typically above $60 \%$. A wider range of field data would be useful for future model development and improved understanding of model components and biophysical characteristics of ground cover.

Mapping species composition and percent cover of bryophytes in the boreal forest is important for quantifying the effects of global change because boreal forests are the second largest forest biome and bryophytes are an important vegetation layer of boreal forests (Bond-Lamberty \& Gower, 2007; Gower et al., 2001), bryophytes have a profound impact on terrestrial carbon, water and nutrient budgets (Turetsky, 2003), bryophytes are sensitive to pollution (Turetsky, 2003) and disturbance (Bond-Lamberty et al., 2004). Bryophytes can also comprise almost $50 \%$ of site productivity in this region (Bond-Lamberty et al., 2004). The importance of bryophytes thus warrants greater effort to develop remote sensing approaches to characterize the composition and percent cover of bryophytes to improve carbon budgets for the boreal forest biome. One approach has been to use remote sensing to map major forest types and by association assign a bryophyte ground layer type (Rapalee et al., 2001). This approach may be reasonable because the water table influences overstory canopy development and bryophyte species composition (Bisbee et al., 2001). For example, poorly-drained, open-canopy black spruce forests are dominated by sphagnum in the ground layer while well-drained, more closed-canopy black spruce forests contain feathermosses in the ground layer. However, this approach does not account for successional changes in bryophytes (Bond-Lamberty et al., 2004) or canopy development (Vogel \& Gower, 1998).

Although both feathermoss and sphagnum can be modeled using only one sensor, this case study demonstrated significant improvements in characterizing bryophyte composition when both CASI and SLICER were used. We speculate that a combination of sensors is needed to distinguish the biophysical characteristics and major functional species groups of the different vegetation strata (overstory, understory and bryophytes), which is important because they each have different light use efficiency coefficients and carbon balance (O'Connell et al., 2003a,b). Future research should include a greater geographical range of site conditions and use of multiple remote sensing instruments to improve prediction and modeling of bryophyte cover.

\section{Acknowledgements}

This research was supported by a NASA grant NNG04GL26G to S.T. Gower. We thank the numerous researchers responsible for the collection of the field and remote sensing data and the ORNL DAAC for public availability. We also thank the NASA Goddard Space Flight Center for providing access to the computer programs to read the SLICER data. We also thank Ben Bond-Lamberty for providing survey data at NOBS. 


\section{References}

Bisbee, K. E., Gower, S. T., Norman, J. M., \& Nordheim, E. V. (2001). Environmental controls on ground cover species composition and productivity in a boreal black spruce forest. Oecologia, 129, 261-270.

Bond-Lamberty, B., \& Gower, S. T. (2007). Estimation of stand-level leaf area for boreal bryophytes. Oecologia, 151, 581-592.

Bond-Lamberty, B., Peckham, S. D., Ahl, D. E., \& Gower, S. T. (2007). Fire as the dominant driver of central Canadian boreal forest carbon balance. Nature, 450, 89-93.

Bond-Lamberty, B., Peckham, S. D., Gower, S. T., \& Ewers, B. E. (in press). Effects of fire on regional evapotranspiration in the central Canadian boreal forest. Global Change Biology. doi:10.1111/j.1365-2486.2008.01776.x

Bond-Lamberty, B., Wang, C. W., \& Gower, S. T. (2004). Net primary production and net ecosystem production of a boreal black spruce wildfire chronosequence. Global Change Biology, 10, 473-487.

Bubier, J. L., Rock, B. N., \& Crill, P. M. (1997). Spectral measurements of boreal wetland and forest mosses. Journal of Geophysical Research, 102(D24), 29483-29494.

Campbell, J. L., Burrows, S., Gower, S. T., \& Cohen, W. B. (1999). BigFoot: Characterizing land cover, LAI, and NPP at the landscape scale for EOS/MODIS validation. Field Manual Version 2.1. Environmental Sciences Division, Oak Ridge National Laboratory, Oak Ridge TN. 104 pp.

Chen, J. M., Leblanc, S. G., Miller, J. R., Freemantle, J., Loechel, S. E., et al. (1999). Compact Airborne Spectrographic Imager (CASI) used for mapping biophysical parameters of boreal forests. Journal of Geophysical Research, 104(D22), 27945-27958.

Environment Canada. (2008). Canadian Climate Normals 1971-2000. http://www. climate.weatheroffice.ec.gc.ca/climate_normals/

Gray, L. H., Freemantle, J. R., Shepherd, P. R., Miller, J. R., Harron, J. W., \& Hersom, C. H. (1997, June). Characterization and calibration of the CASI airborne imaging spectrometer for BOREAS.Canadian Journal of Remote Sensing, 23(2), 188-195 (Special issue on BOREAS).

Gower, S. T., \& Kirschbaum, A. A. (2008). BigFoot field data for North American Sites, 1999-2003. Data set. Available on-line [http:/ / www.daac.ornl.gov] from Oak Ridge National Laboratory Distributed Active Archive Center, Oak Ridge, Tennessee, U.S.A. doi:10.3334/ORNLDAAC/868

Gower, S. T., Krankina, O., Olson, R. J., Apps, M., Linder, S., \& Wang, C. (2001). Net primary production and carbon allocation patterns of boreal forest ecosystems. Ecological Applications, 11(5), 1395-1411.

Gower, S. T., Vogel, J. G., Norman, J. M., Kucharik, C. J., Steele, S. J., \& Stow, T. K. (1997). Carbon distribution and aboveground net primary production in aspen, jack pine, and black spruce stands in Saskatchewan and Manitoba, Canada. Journal of Geophysical Research, 102(24), 29,029-29,041.

Harding, D. J. (2000). BOREAS Scanning Lidar Imager of Canopies by Echo Recovery (SLICER): Level-3 Data. CD-ROM. Available by special arrangement with Oak Ridge National Laboratory Distributed Active Archive Center, Oak Ridge, Tennessee, U.S.A. [http://www.daac.ornl.gov].

Harding, D. J., Lefsky, M. A., Parker, G. G., \& Blair, J. B. (2001). Laser altimeter canopy height profiles: Methods and validation for closed-canopy, broadleaf forests. Remote Sensing of Environment, 76, 283-297.

Kotchenova, S. Y., Song, X., Shabanov, N. V., Potter, C. S., Knyazikhin, Y., \& Myneni, R. B. (2004). Lidar remote sensing for modeling gross primary production of deciduous forests. Remote Sensing of Environment, 92, 158-172.
Lefsky, M. A., Cohen, W. B., Acker, S. A., Parker, G. G., Spies, T. A., \& Harding, D. (1999). Lidar remote sensing of the canopy structure and biophysical properties of Douglas-fir western hemlock forests. Remote Sensing of Environment, 70, 339-361.

Lefsky, M. A., Cohen, W. B., Harding, D. J., Parker, G. G., Acker, S. A., \& Gower, S. T. (2002) Lidar remote sensing of above-ground biomass in three biomes. Global Ecology E Biogeography, 11, 393-399.

Lefsky, M. A., Harding, D., Cohen, W. B., Parker, G., \& Shugart, H. H. (1999). Surface lidar remote sensing of basal area and biomass in deciduous forests of eastern Maryland, USA. Remote Sensing of Environment, 67, 83-98.

Miller, J. R. (2000). BOREAS RSS-19 1996 CASI At-Sensor Radiance and Reflectance Images Data set. Available on-line [http://www.daac.ornl.gov] from Oak Ridge National Laboratory Distributed Active Archive Center, Oak Ridge, Tennessee, U.S.A.

Ni-Meister, W., Jupp, D. L. B., \& Dubayah, R. (2001). Modeling lidar waveformas in heterogeneous and discrete canopies. IEEE Transactions on Geoscience and Remote Sensing, 39(9), 1943-1958.

O'Connell, K. E., Gower, S. T., \& Norman, J. M. (2003). Comparison of net primary production and light-use dynamics of two boreal black spruce forest communities. Ecosystems, 6 236-247.

O'Connell, K. E., Gower, S. T., \& Norman, J. M. (2003). Net ecosystem production of two contrasting boreal black spruce forest communities. Ecosystems, 6, 248-260.

O'Neill, N. T., Zagolski, F., Bergeron, M., Royer, A., Miller, J., \& Freemantle, J. (1997) Atmospheric correction validation of CASI images acquired over the BOREAS southern study area.Canadian Journal of Remote Sensing, 23(2), 143-162 (Special issue on BOREAS).

Rapalee, G., Steyaert, L. T., \& Hall, F. G. (2001). Moss and lichen cover mapping at local and regional scales in the boreal forest ecosystem of central Canada. Journal of Geophysical Research Atmospheres, 106, 33,551-33,563.

Sellers, P. J., Hall, F., Margolis, H., Kelly, B., Baldocchi, D., Denhartog, G., et al. (1995). The boreal ecosystem-atmosphere study (BOREAS) - An overview and early results from the 1994 field year. Bulletin of the American Meteorological Society, 76(9), $1549-1577$

Serbin, S. P., Gower, S. T., \& Ahl, D. E. (2009). Canopy dynamics and phenology of a borea black spruce wildfire chronosequence. Agricultural and Forest Meteorology, 149(1), 187-204.

Skre, O., \& Oechel, W. C. (1981). Moss functioning in different taiga ecosystems in interior Alaska.1. Seasonal, phenotypic, and drought effects on photosynthesis and response patterns. Oecologia, 48, 50-59.

Steyaert, L. T., Hall, F. G., \& Loveland, T. R. (1997). Land cover mapping, fire regeneration, and scaling studies in the Canadian boreal forest with $1 \mathrm{~km}$ AVHRR and Landsat TM data. Journal of Geophysical Research-Atmospheres, 102(D24), 29581-29598.

Turetsky, M. R. (2003). The role of bryophytes in carbon and nitrogen cycling. Bryologist, 106(3), 395-409.

Vogel, J. G., \& Gower, S. T. (1998). Carbon and nitrogen dynamics of boreal jack pine stands with and without a green alder understory. Ecosystems, 1(4), 386-400.

Whitehead, D., \& Gower, S. T. (2001). Photosynthesis and light-use efficiency by plants in a Canadian boreal forest ecosystem. Tree Physiology, 21(12-13), 925-929. 